Article

\title{
Influence of Polymer Concentration and Nozzle Material on Centrifugal Fiber Spinning
}

\author{
Jorgo Merchiers ${ }^{1,2}$, Willem Meurs ${ }^{1,2}$, Wim Deferme ${ }^{1,2} \mathbb{E}$, Roos Peeters ${ }^{1,2}\left(\mathbb{D}\right.$, Mieke Buntinx ${ }^{1,2} \mathbb{E}$ \\ and Naveen K. Reddy $1,2, * \mathbb{D}$ \\ 1 Hasselt University, Institute for Materials Research (IMO-IMOMEC), B-3590 Diepenbeek, Belgium; \\ jorgo.merchiers@uhasselt.be (J.M.); Willemmeurs@gmail.com (W.M.); wim.deferme@uhasselt.be (W.D.); \\ roos.peeters@uhasselt.be (R.P.); mieke.buntinx@uhasselt.be (M.B.) \\ 2 IMEC vzw-Division IMOMEC, Wetenschapspark 1, B-3590 Diepenbeek, Belgium \\ * Correspondence: naveen.reddy@uhasselt.be; Tel.: +32(0)11-29-2186
}

Received: 7 February 2020; Accepted: 3 March 2020; Published: 5 March 2020

\begin{abstract}
Centrifugal fiber spinning has recently emerged as a highly promising alternative technique for the production of nonwoven, ultrafine fiber mats. Due to its high production rate, it could provide a more technologically relevant fiber spinning technique than electrospinning. In this contribution, we examine the influence of polymer concentration and nozzle material on the centrifugal spinning process and the fiber morphology. We find that increasing the polymer concentration transforms the process from a beaded-fiber regime to a continuous-fiber regime. Furthermore, we find that not only fiber diameter is strongly concentration-dependent, but also the nozzle material plays a significant role, especially in the continuous-fiber regime. This was evaluated by the use of a polytetrafluoroethylene (PTFE) and an aluminum nozzle. We discuss the influence of polymer concentration on fiber morphology and show that the choice of nozzle material has a significant influence on the fiber diameter.
\end{abstract}

Keywords: centrifugal fiber spinning; nonwoven fibers; polymer rheology; wall slip

\section{Introduction}

Microfibers and nanofibers exhibit an extremely high surface-to-volume ratio, a low density, and a high pore volume [1-3]. These exceptional properties offer high added value to the material, making them suitable for a wide range of applications in the fields of environment [4-6], biomedical technology [7-9], and energy production [10-14]. Nonwoven fiber mats are generally obtained by the use of electrospinning, in which a polymeric fluid jet is pushed from a nozzle, where it is exposed to a high electric field. Here, the charged jet will be subjected to whipping and bending instabilities, leading to thinning of the jet and evaporation of the solvent [15-17]. However, due to a relatively low production rate $(0.01-0.1 \mathrm{~mL} / \mathrm{min})[18,19]$ and the need for high voltages, the search for better alternative spinning techniques is necessary.

Centrifugal fiber spinning can be considered as a promising alternative to conventional spinning techniques, such as electrospinning and melt-blow spinning. It is a very simple technique, based on centrifugal forces, and offers a higher production rate at a lower cost. This leads to a technology that is environmentally as well as economically advantageous over others. This highly versatile method was first developed by the FibeRio Technology Corporation and introduced as the Forcespinning Technology ${ }^{\circledR}[20]$. Subsequent experimental and theoretical studies revealed that the process involves three stages, schematically depicted in Figure 1. These are: the jet initiation stage (I), the jet-elongation stage (II), and the solvent evaporation stage (III), each characterized by a proper timescale. The characteristic time for the jet-initiation stage, $\tau_{1}$, is proportional to the inverse of the critical rotational 
speed, $\Omega_{\mathrm{cr}}$. Here the centrifugal force must overcome the surface tension at the nozzle tip to initiate jet formation. In the jet-elongation stage, the viscous forces counteract the centrifugal forces. Here the characteristic timescale, $\tau_{2}$, is mainly determined by the shear and extensional viscosity, as well as the density $(\rho)$ of the polymer solution. Finally, the third characteristic timescale, $\tau_{3}$, is determined by the diffusion coefficient (D), of the solvent through the drying polymer with jet radius, $r$ [21-25]. According to several published studies, the fiber morphology depends on the polymer concentration, molecular weight, centrifugal speed, collector distance, and nozzle diameter [26-29]. Even though the centrifugal spinning technique has attracted a lot of interest, and the number of publications has increased tremendously due to its simplicity and its ability to produce fibers at a large scale, control over the fiber morphology remains the major limitation to upscaling [29-45].

I.

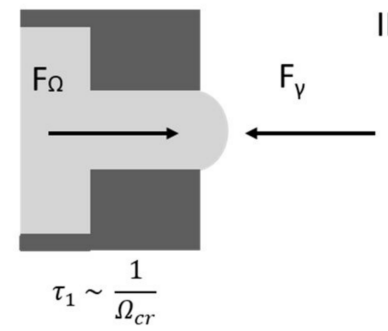

II.

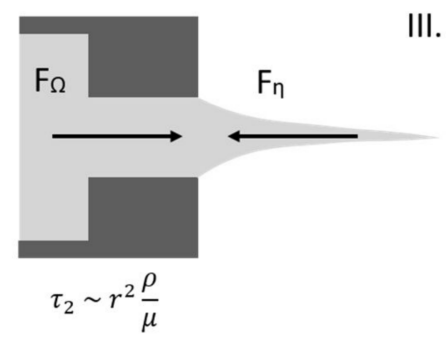

III.

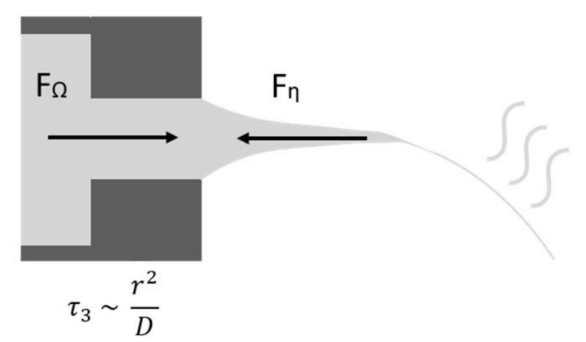

Figure 1. The three stages in centrifugal fiber spinning experiments, being the jet initiation (I), jet extension (II) and solvent evaporation (III), with their respective timescales.

In this contribution, we investigate the role of both concentration-dependent variation in shear viscosity and the choice of nozzle material on the fiber morphology. Although most of the literature on the centrifugal spinning technique focuses on variations in rotational speed, nozzle diameter, and collector distance, we seek to determine whether certain events inside the centrifuge nozzle influence the fiber morphology, i.e., average fiber diameter, diameter distribution, and bead formation. We provide results from a systematic study of the effect of polymer concentration and nozzle material on the fiber morphology and average diameter by means of a home-built centrifugal spinning setup. We experimentally show the influence of polymer concentration on the fiber morphology. The focus was set on the concentration range where there is a transition from bead-on-string to continuous fiber morphology. We show that a smooth morphology transition occurs as a function of polymer concentration from beads-on-string to continuous fibers, but when plotted as a function of fiber diameter the same transition is very sharp, showing two distinct slopes. Finally, we show that the choice of nozzle material can be considered as a novel parameter that has a significant influence on the outcome of the centrifugal spinning process. By comparing the morphological results of fibers spun from two different nozzle materials, a significant difference in concentration dependence was observed.

\section{Materials and Methods}

\subsection{Materials}

Polystyrene (PS, $\mathrm{M}_{\mathrm{W}}=190 \mathrm{~kg} / \mathrm{mol}$ ) and tetrahydrofuran (THF, AnalaR NORMAPUR) were purchased from VWR Chemicals (Oud-Heverlee, Belgium) and used without further purification. Polymer solutions were prepared by slowly adding the polymer to the solvent under continuous magnetic stirring. Homogeneous mixing was ensured by stirring for around $24 \mathrm{~h}$ in hermetically sealed vials. A concentration range of $10.0-25.0 \mathrm{wt} \%$, in steps of $2.5 \mathrm{wt} \%$, was prepared.

\subsection{Rheological Characterization}

The shear viscosity of the different PS solutions was measured using an ARG2 stress-controlled rheometer (TA Instruments, New Castle, DE, USA), with cone-and-plate geometry ( $40 \mathrm{~mm}$ diameter, $1^{\circ}$ cone angle). The temperature was fixed at $25^{\circ} \mathrm{C}$ using a Peltier element and a solvent trap was used 
to reduce evaporation. Steady-state viscosity was recorded for shear stress values ranging from 0.01 to $10 \mathrm{~Pa}$ within the experimentally accessible window of the rheometer. A steady-state tolerance of $3 \%$ was applied to each measurement.

\subsection{Fiber Characterization}

The morphology of the PS fibers was analyzed using a Hitachi TM3000 tabletop scanning electron microscope (SEM) (Hitachi, Tokyo, Japan). Samples were imaged at $15 \mathrm{kV}$ with a $5 \mathrm{~mm}$ working distance. The image analysis was carried out by means of ImageJ software (Bethesda, MD, USA). Sampling of the fibers was done in such a way that at least 100 fibers were measured, evenly divided over at least three different SEM images, which were taken at random spots on each sample. This was done to obtain statistically reliable fiber diameters. The fiber diameter distributions are presented together with the SEM images in this paper.

\subsection{Contact Angle}

THF was used as a testing liquid, and was deposited as $2-\mu \mathrm{L}$ droplets by a Hamilton syringe onto the substrates (Aluminum and PTFE). A software-controlled needle dosing system (DSA 100E, KRÜSS $\mathrm{GmbH}$, Hamburg, Germany) was used for static sessile drop contact angle measurements. The contact angles were measured after stabilization of the drop shape (typically after $5 \mathrm{~s}$ ) and are reported as an average of five measurements.

\subsection{Force to Push Polymer Solution from Different Nozzle Materials}

The force measurements were performed using an MTS Systems (Adamel Lhomargy tensile tester, Roissy-en-Brie, France) at a crosshead speed of $500 \mathrm{~mm} / \mathrm{min}$. For these experiments, a 10-mL glass syringe was used, on which both the aluminum and PTFE nozzles, used to obtain PS fibers, could be fitted via a metal Luer lock connection. The polymer solutions were pushed at a controlled flow rate of $75 \mathrm{~mL} / \mathrm{min}$ through the nozzle. A set of three measurements was performed for each solution.

\section{Results}

\subsection{Fiber Spinning Setup}

A home-built centrifugal spinning setup with an arm-style spinneret and a novel lifting system was developed as shown in Figure 2. With this system, the stacking of fibers on top of each other could be reduced, leading to more open and aligned fiber mats. Polymer solution is added via a syringe pump to the rotating spinneret at a constant flow rate of $1 \mathrm{~mL} / \mathrm{min}$. The flow rate at which the polymer jet is ejected is controlled by the stress at the nozzle tip due to centrifugal force. The flow rate of 1 $\mathrm{mL} / \mathrm{min}$ was empirically determined to be sufficient to have a continuous flow of polymer solution within the nozzle. The spinneret was equipped with a screw thread to interchange different types of nozzle tips as needed. Nozzle tips with a nozzle diameter of $0.6 \mathrm{~mm}$ were fabricated in both aluminum and PTFE.

The collector poles were set $12 \mathrm{~cm}$ from the nozzle tip and fibers were produced at a rotation speed of $4000 \mathrm{rpm}$. Furthermore, fiber spinning experiments were always carried out at room temperature $\left(22{ }^{\circ} \mathrm{C}\right.$ ) and at a relative humidity of approximately $40 \%$. (A detailed sketch of the spinneret design is provided in Figure S1.) 

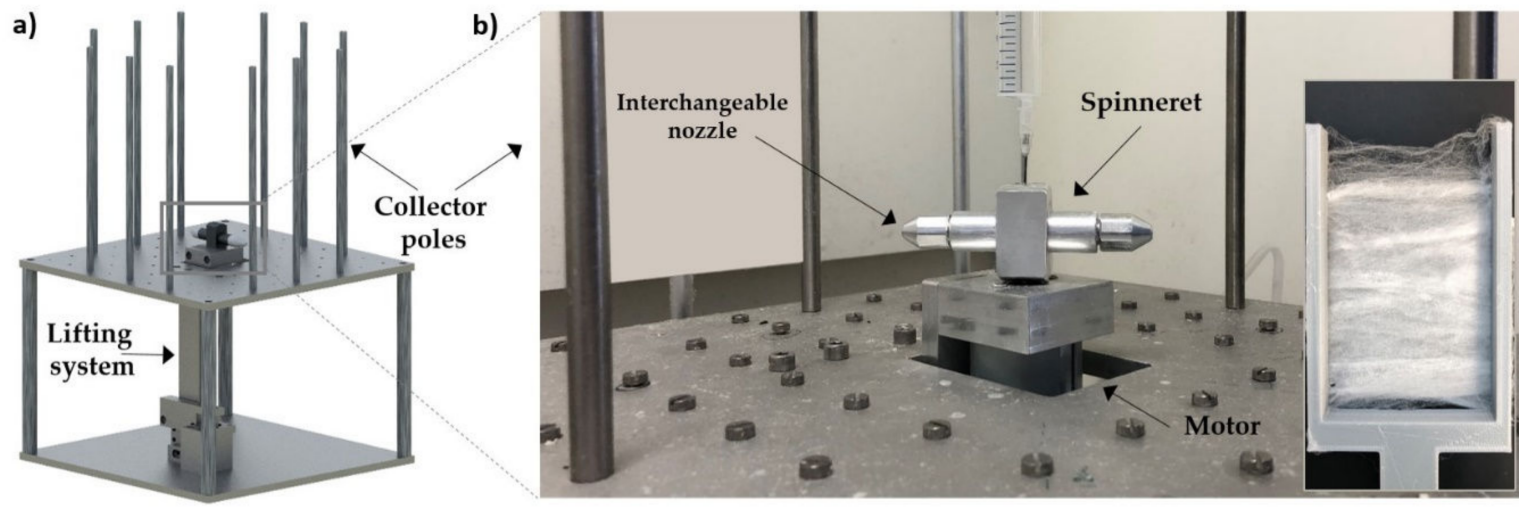

Figure 2. (a) Schematic view of the fiber spinning centrifuge with lift system. (b) The fiber spinneret with an interchangeable nozzle in which the polymer solution is added via the syringe on top (which is connected to a syringe pump to control the solution flow rate). The inset in (b) shows a macroscopic picture of the aligned fibers.

\subsection{Characterization of Polymer Solutions}

The steady shear viscosity measurements were carried out for a wide range of concentrations ranging from 1.0 to $25.0 \mathrm{wt} \%$, as shown in Figure 3a. The viscosity measurements were carried out for a range of shear stresses set by the accessible torque range of the rheometer. The limits of the instrument were considered to avoid erroneous data, and are depicted by the gray zones in Figure 3a.

The low torque limit was determined via [46]

$$
\eta>\frac{\mathrm{F}_{\tau} \mathrm{T}_{\min }}{\dot{\gamma}}
$$

where $\eta$ is the shear viscosity and $\dot{\gamma}$ is the shear rate.

Furthermore, $F_{\tau}=3 /\left(2 \pi R^{3}\right)$ with measuring geometry radius, $\mathrm{R}=20 \mathrm{~mm}$, and minimum measurable torque, $\mathrm{T}_{\min }=0.1 \mu \mathrm{N} \cdot \mathrm{m}$. At higher shear rates, the limit is set by secondary flow in the sample due to inertia $[47,48]$, and is given by

$$
\eta>\frac{L^{3} / R}{\operatorname{Re}_{\text {crit }}} \rho \dot{\gamma},
$$

where the critical Reynolds number $\operatorname{Re}_{\text {crit }}=4$, the maximum gap between the cone edge and plate is $\mathrm{L}=0.7 \mathrm{~mm}$ and the density of THF $\rho=889 \mathrm{~kg} / \mathrm{m}^{3}$.

The specific viscosity at each concentration was calculated by the following equation [48]:

$$
\eta_{\mathrm{sp}}=\frac{\eta_{0}-\eta_{\mathrm{s}}}{\eta_{\mathrm{s}}}
$$

where $\eta_{0}$ is the zero-shear viscosity determined for every concentration from Figure $3 \mathrm{a}$ and $\eta_{\mathrm{s}}$ is the solvent viscosity $=0.46 \mathrm{mPa} \cdot \mathrm{s}$. The critical overlap concentration $\left(\mathrm{c}^{*}\right)$ of the PS chains in THF was estimated by the following equation [49]:

$$
c^{*}=\frac{0.77}{[\eta]}
$$

in which [ $\eta$ ] is the intrinsic viscosity. The critical overlap concentration, $c^{*}$, was determined to be 0.012 $\mathrm{g} / \mathrm{mL}$ using Equation (4), through which the intrinsic viscosity, $[\eta]=65.24 \mathrm{~mL} / \mathrm{g}$, was experimentally determined via the Mark-Houwink equation using gel permeation chromatography (GPC). The Mark-Houwink equation is:

$$
[\eta]=\mathrm{K} \times \mathrm{M}_{\mathrm{V}}^{\alpha}
$$


in which K and $\alpha$ are the Mark-Houwink parameters, determined to be $0.0141 \mathrm{~mL} / \mathrm{g}$ and 0.70 , respectively. The experimentally determined viscosity averaged molecular weight (by GPC), $171.9 \mathrm{~kg} / \mathrm{mol}$, was used to calculate the intrinsic viscosity. The intrinsic viscosity obtained here is similar to the values found in the literature for PS in a good solvent [50,51]. Previous studies on electrospinning show that topological interactions become relevant above the critical entanglement concentration, $\mathrm{c}_{\mathrm{e}} \approx 10 \mathrm{c}^{*}$ for flexible polymers [52-56]. In the case of narrow disperse samples (without high $\mathrm{M}_{\mathrm{w}}$ content), the solution with a concentration below $c^{*}$ does not possess the required viscoelastic forces to overcome the instabilities that are exerted on the liquid jet, leading to jet breakup and bead formation. In the case of disperse samples, the influence of the high $\mathrm{M}_{\mathrm{w}}$ content in the sample will change the viscoelastic response of the polymers. This will cause a significant decrease in the critical concentration at which fibers can be spun, leading to jet breakup and drop formation at lower concentrations than the predicted critical values $[26,27,49,52,54]$.

a)

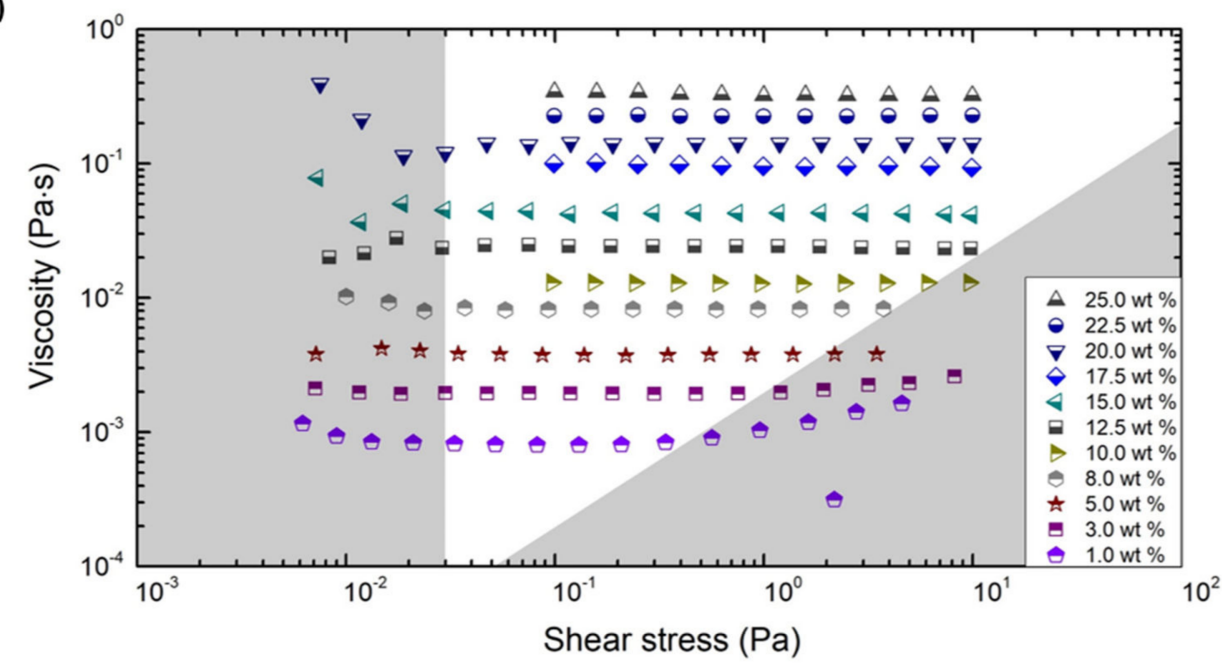

b)

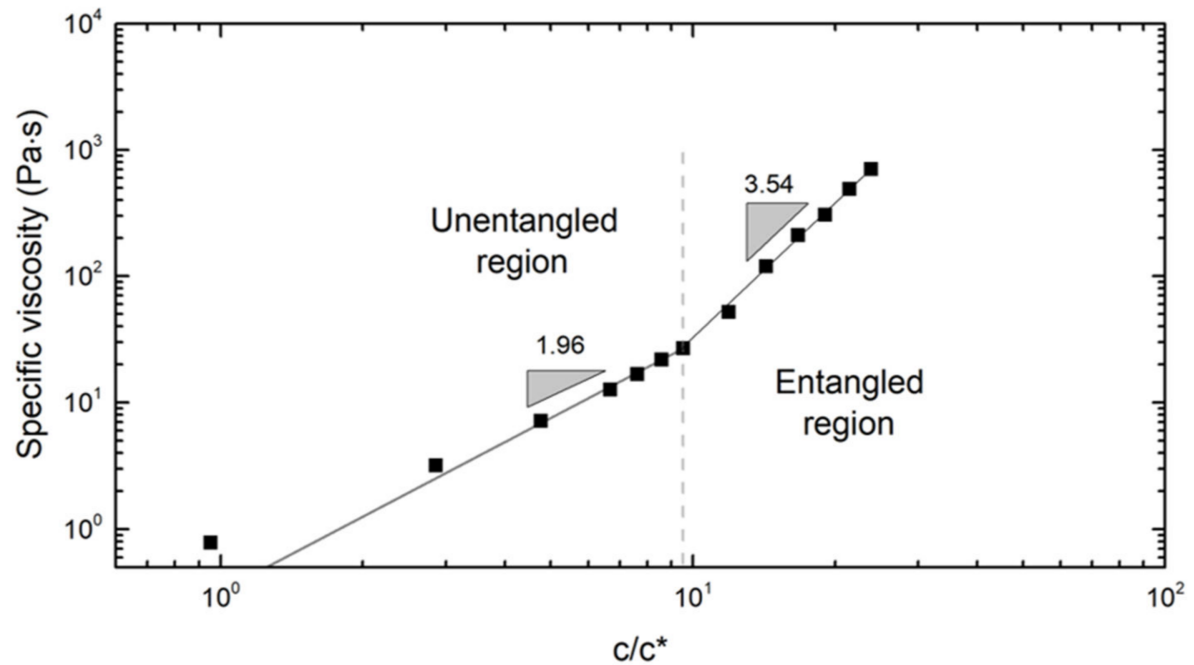

Figure 3. (a) Steady shear viscosity as a function of shear stress. The region between the gray zones is the accessible window of the rheometer. (b) Specific viscosity as a function of PS concentration normalized with overlap concentration $\left(c^{*}\right)$.

Figure $3 b$ shows a plot of the specific viscosity, $\eta_{\mathrm{sp}}$, as a function of the polymer concentration normalized by the overlap concentration, $\mathrm{c} / \mathrm{c}^{*}$. Since the $1 \mathrm{wt} \%(=0.011 \mathrm{~g} / \mathrm{mL})$ solution lies below the $c^{*}(=0.012 \mathrm{~g} / \mathrm{mL})$, this point will not correspond with the power law exponent and therefore deviates significantly from the fitted line. The entanglement concentration, $c_{e}$, was determined as the point 
where an abrupt change in the power law relation between both variables occurred. The power law exponent increased from 1.96 to 3.54 at a rescaled concentration value of $\mathrm{c} / \mathrm{c}^{*}=9.53$, which corresponds to the entanglement concentration of $\mathrm{c}_{\mathrm{e}} \approx 0.112 \mathrm{~g} / \mathrm{mL}$ ( $=10.0 \mathrm{wt} \%$ ).

This is in agreement with literature values, where the power law relations of an unentangled polymer solution are $\eta_{\mathrm{sp}} \propto\left(\mathrm{c} / \mathrm{c}^{*}\right)^{2}$ and for an entangled polymer solution $\eta_{\mathrm{sp}} \propto\left(\mathrm{c} / \mathrm{c}^{*}\right)^{3.9}$ in a good solvent $[57,58]$. In other words, beyond $c_{e}$ the change in viscosity becomes more sensitive to changes in polymer concentration. All the centrifugal fiber spinning experiments were therefore conducted with polymer solutions starting at this critical concentration of $10.0 \mathrm{wt} \%$. Zero shear viscosity and specific viscosity at various polymer concentrations are also presented in Table 1.

Table 1. Experimentally determined values of the zero-shear viscosity $\left(\eta_{0}\right)$ and specific viscosity $\left(\eta_{\mathrm{sp}}\right)$ of PS solutions, diameter $(\Phi)$ and standard deviation (SD) of polymer fibers obtained for each PS concentration using aluminum (ALU) and PTFE nozzles.

\begin{tabular}{|c|c|c|c|c|c|c|}
\hline$c(w t \%)$ & $\eta_{0}(\mathrm{~Pa} \cdot \mathrm{s})$ & $\eta_{\mathrm{sp}}(-)$ & $\Phi(\mathrm{ALU})(\mu \mathrm{m})$ & $\mathrm{SD}(\mu \mathrm{m})$ & $\Phi$ (PTFE) $(\mu \mathrm{m})$ & $\overline{S D}(\mu \mathrm{m})$ \\
\hline 12.5 & 0.024 & 52.0 & 1.13 & 0.77 & 0.76 & 0.63 \\
\hline 17.5 & 0.098 & 212.0 & 1.68 & 1.19 & 2.46 & 2.30 \\
\hline 20.0 & 0.142 & 307.3 & 3.00 & 2.94 & 5.42 & 4.70 \\
\hline 22.5 & 0.226 & 490.3 & 10.10 & 5.79 & 8.08 & 5.44 \\
\hline
\end{tabular}

\subsection{Changes to Fiber Morphology with Polymer Concentration}

Figure 4 shows the SEM images of the fiber morphology obtained for a range of different concentrations of PS in THF, together with the fiber diameter distributions. To prevent the formation of fibers at lower rotational speeds during startup, the spinneret was started and left spinning until it reached $4000 \mathrm{rpm}$ before dispensing the polymer solution. Below a polymer concentration of $10.0 \mathrm{wt} \%$, only beads were formed due to the lack of sufficient viscoelastic stresses required to prevent capillary breakup [52]. The experimental lower limit of $10.0 \mathrm{wt} \%$ to form fibers agrees with the entanglement concentration $\left(c_{e} \approx 10 c^{*}\right)$, as calculated before from the overlap concentration $\left(c^{*}\right)$. Above $25.0 \mathrm{wt} \%$, the solution's viscosity was too high for the centrifugal force to overcome the viscous force.

The fiber diameter and its distribution (in terms of standard deviation) for the intermediate concentrations obtained using the aluminum nozzle are shown in Table 1 . The tabulated values were determined by averaging at least 100 fibers in the sample. In Figure 4, two phenomena can be observed upon increasing the polymer concentration: 1) Beads-on-a-String (BOAS) morphology with a slow increase in fiber diameter at lower concentrations, which is shown in Figure 4a-c (from 10.0 to $15.0 \mathrm{wt}$ $\%$ ), and 2) bead-free fiber morphology with a sharp increase in diameter for higher concentrations, which is shown in Figure $4 \mathrm{~d}-\mathrm{f}(>17.5 \mathrm{wt} \%)$.

Fiber spinning experiments of the same polymer solutions, spun from a PTFE nozzle with exactly the same dimensions, are shown in Figure 5. The results from these experiments are also listed in Table 1, from which a similar trend as with the aluminum nozzle was observed for the two concentration regions: a slow increase in fiber diameter in the presence of beads for the lower polymer concentrations, and a fast increase in fiber diameter with no beads at higher polymer concentrations. Also, the transition from beaded fibers to continuous fibers occurred in the same region as it did for the aluminum nozzle. The fiber morphology using PTFE is similar to what has been seen in the literature [59-61]. However, a significant difference was observed in the dependence of the fiber diameter on the polymer concentration between the fibers spun from both nozzles as shown in Table 1. 


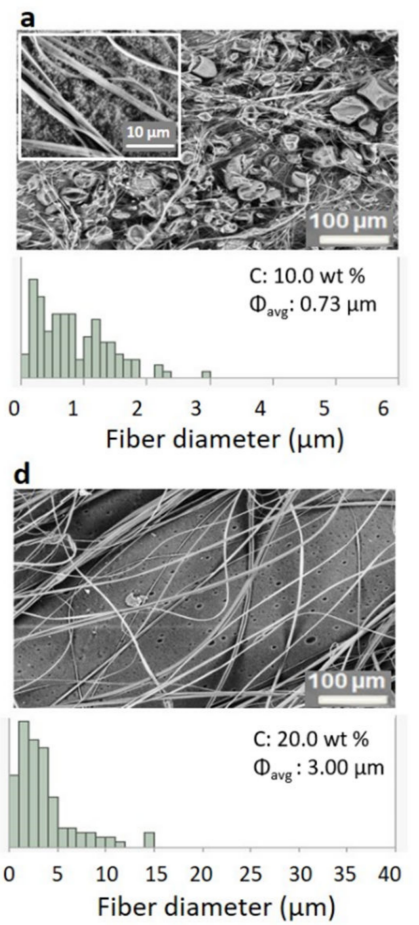

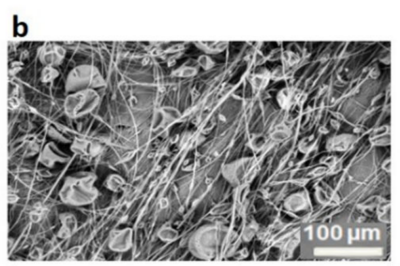
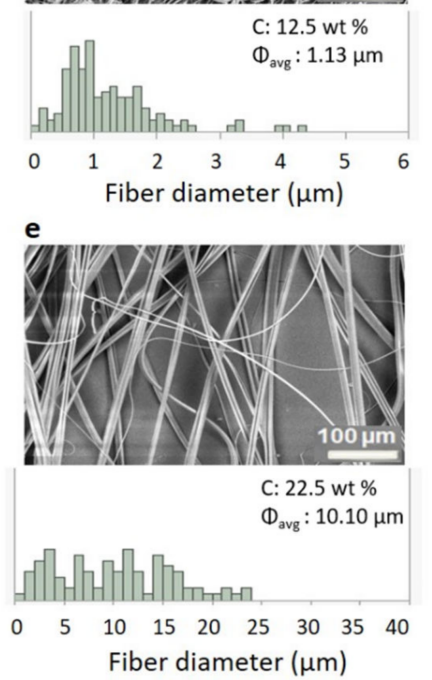
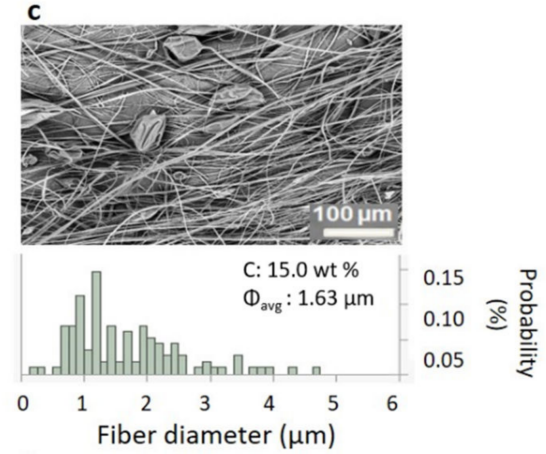

f

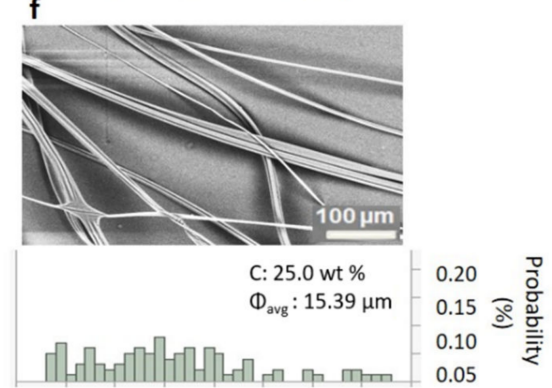

$\begin{array}{lllllllll}0 & 5 & 10 & 15 & 20 & 25 & 30 & 35 & 40\end{array}$ Fiber diameter $(\mu \mathrm{m})$

Figure 4. SEM images of fibers spun from the aluminum nozzle at different polymer concentrations and their corresponding diameter distribution. Inset in (a) is an enlargement (30 $\mathrm{m}$ image width) showing the presence of fibers. (Note: the fiber diameter on the x-axis is from 0 to $6 \mu \mathrm{m}$ for $(\mathbf{a}-\mathbf{c})$, and from 0 to $40 \mu \mathrm{m}$ for $(\mathbf{d}-\mathbf{f}))$.

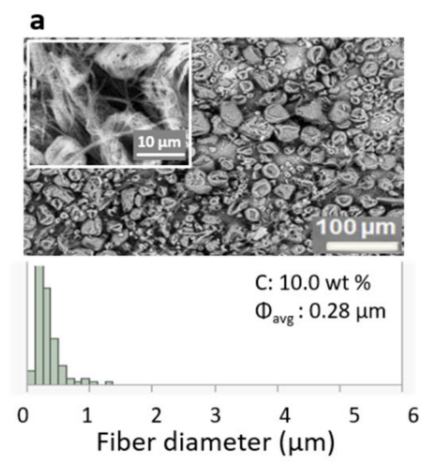

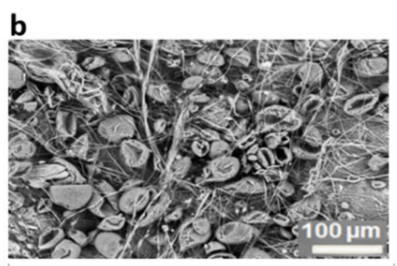
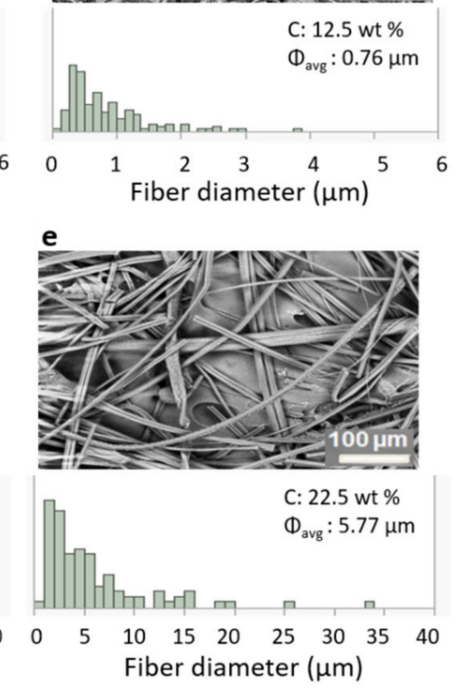
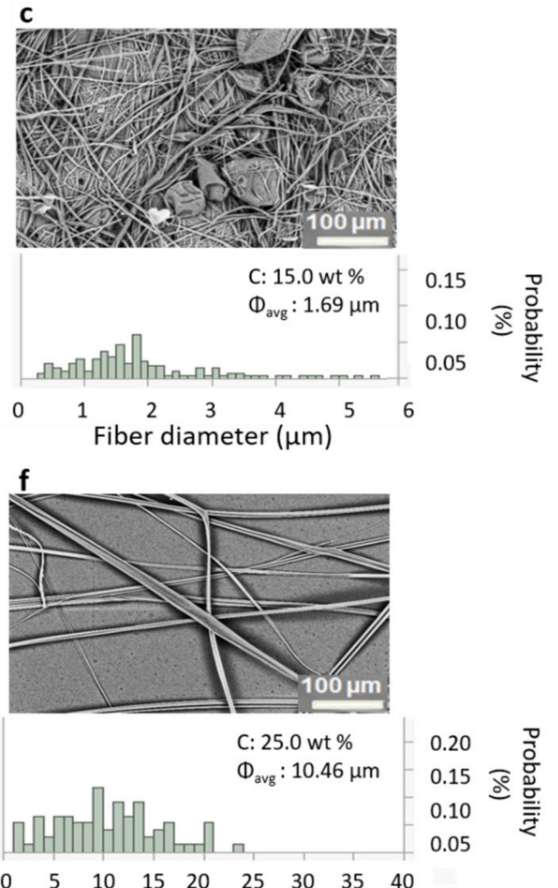

Fiber diameter $(\mu \mathrm{m})$

Figure 5. SEM images of fibers spun from the PTFE nozzle at different polymer concentrations and their corresponding diameter distribution. The inset in (a) is an enlargement (30 $\mu \mathrm{m}$ image width) showing the presence of fibers. (Note: the fiber diameter scale is from 0 to $6 \mu \mathrm{m}$ for $(\mathbf{a}-\mathbf{c})$, and from 0 to $40 \mu \mathrm{m}$ for $(\mathbf{d}-\mathbf{f}))$. 


\section{Discussion}

\subsection{Fiber Morphology}

BOAS morphology: For concentrations close to $c_{e}$, the polymer jets' viscoelastic stress is sufficient to withstand the capillary breakup, leading to fiber formation. At this transition concentration, the capillary instabilities will be significant when the polymer jet is still thick, but as the jet thins the viscoelastic stress becomes significant due to the high extensional rates. This event will eventually lead to the BOAS morphology [62-64]. As most of the bulk polymer is in the bead part, the string connecting the beads will drain into the beads, thinning the string further $[65,66]$. This process, in combination with solvent evaporation, leads to extremely thin solid fibers whenever there is a BOAS morphology. As the concentration is increased, the fiber diameter increases slowly, reducing the size and number of the beads (see Figures 4 and $5 \mathrm{a}-\mathrm{c}$ ).

Continuous fiber morphology: In Figures 4 and $5 \mathrm{~d}-\mathrm{f}$, no more beads were observed for solutions of concentrations $>17.5 \mathrm{wt} \%$. In these solutions, the viscoelastic forces are strong enough to counteract capillary breakup to avoid the formation of beads. This will lead to a faster increase of the fiber diameter upon further increase of concentration, as the bulk material must stay in the fiber-unlike for lower concentrations, where it could drain into the beads. Additionally, other factors like the increase in viscosity and solvent evaporation (which leads to skin formation on the polymer jets) also come into play [39].

\subsection{Polymer Solution-Wall Interactions}

One of the events that plays a role inside the nozzle is the interaction between the polymer solution and the nozzle wall [67-72]. Unlike in electrospinning, where the polymer solution is dispensed at extremely low flow rates, in centrifugal spinning the flow rates are much higher, leading to high shear rates within the nozzle. In general, the no-slip boundary condition at the nozzle wall is assumed in the bulk flow of fluids. However, this no-slip boundary condition will not be valid for many complex fluids, such as polymer solutions. Especially at higher polymer concentrations things become even more complicated when a thin polymer-depleted layer of much lower viscosity than the bulk solution forms at the solid boundary, in which the surface wettability plays a crucial role [73-77]. One of the open questions in centrifugal spinning that has not been dealt with in detail, to our knowledge, is the effect of nozzle material on the final fiber morphology.

The contact angle, which is a measure of wettability, was determined using the solvent (THF) on both an aluminum $\left(16^{\circ}\right)$ and a PTFE $\left(25^{\circ}\right)$ substrate. These low contact angles indicate that the interfacial tension between solvent and nozzle is small, leading to the no-slip boundary condition for the pure solvent. However, to assess the presence of slip within the nozzle during flow, we directly measured the force required to push the polymer solution out of the two nozzles at a fixed flow rate. A lower force needed to push the solution implies relatively more wall slip as compared to a higher force. Figure 6 shows the difference in stress (force/nozzle cross section area) required for the flow of the polymer solutions through the PTFE and the aluminum nozzle. The difference between the stress needed to push pure THF through both nozzles is similar, with a slightly negative value, meaning that it takes marginally more force to push THF through the aluminum nozzle than it does through the PTFE nozzle, in line with the measured contact angles.

The same experiments were conducted for the polymer solutions that were used in the fiber spinning experiments. The relative difference between stress values was also slightly negative for the low concentrated solutions $(<15.0 \mathrm{wt} \%)$, indicating that no significant interactions exist between wall and solution (low-concentration polymer solutions behave similarly to pure THF). For intermediate concentrations (around $15.0 \mathrm{wt} \%$ ), the stress difference shows a steep increase from the lower concentrations, which would imply that there is more slip occurring in the PTFE nozzle. Even though a higher stress difference was seen at this intermediate concentration, there was no sudden change seen in fiber diameter. Currently, no explanation can be provided for this behavior. Once the concentration 
enters the highly concentrated regime $(\geq 17.5 \mathrm{wt} \%)$ where solely continuous fibers were formed, the stress difference suddenly becomes positive, meaning that the force required to push the polymer solution through the PTFE nozzle is higher than that for the aluminum nozzle. This sudden change correlates with the faster increase in fiber diameter for the high concentration regime for fibers spun from the aluminum nozzle as compared to the PTFE one, as tabulated in Table 1. We believe that the reason for this sudden change in force between the nozzles can be assigned to the onset of the 'apparent' wall slip, which occurs to a higher extent in the aluminum nozzle compared to that of PTFE for polymer solutions in THF. The 'apparent' wall slip causes an easier flow, which induces a lower force needed to push the solution in the case of the aluminum nozzle, changing the flow profile in the nozzle into a plug flow. As this plug flow polymer solution is pulled due to centrifugal force, the jet's starting diameter will be large, leading to thicker fibers. In the case of the PTFE nozzle, the higher force required to push the polymer solution implies no or relatively low 'apparent' wall slip, making the flow profile closer to parabolic. This fluid with parabolic flow profile when pulled out of the nozzle leads to a smaller initial jet diameter, which leads to fibers with smaller diameter as compared to fibers produced from the aluminum nozzle.

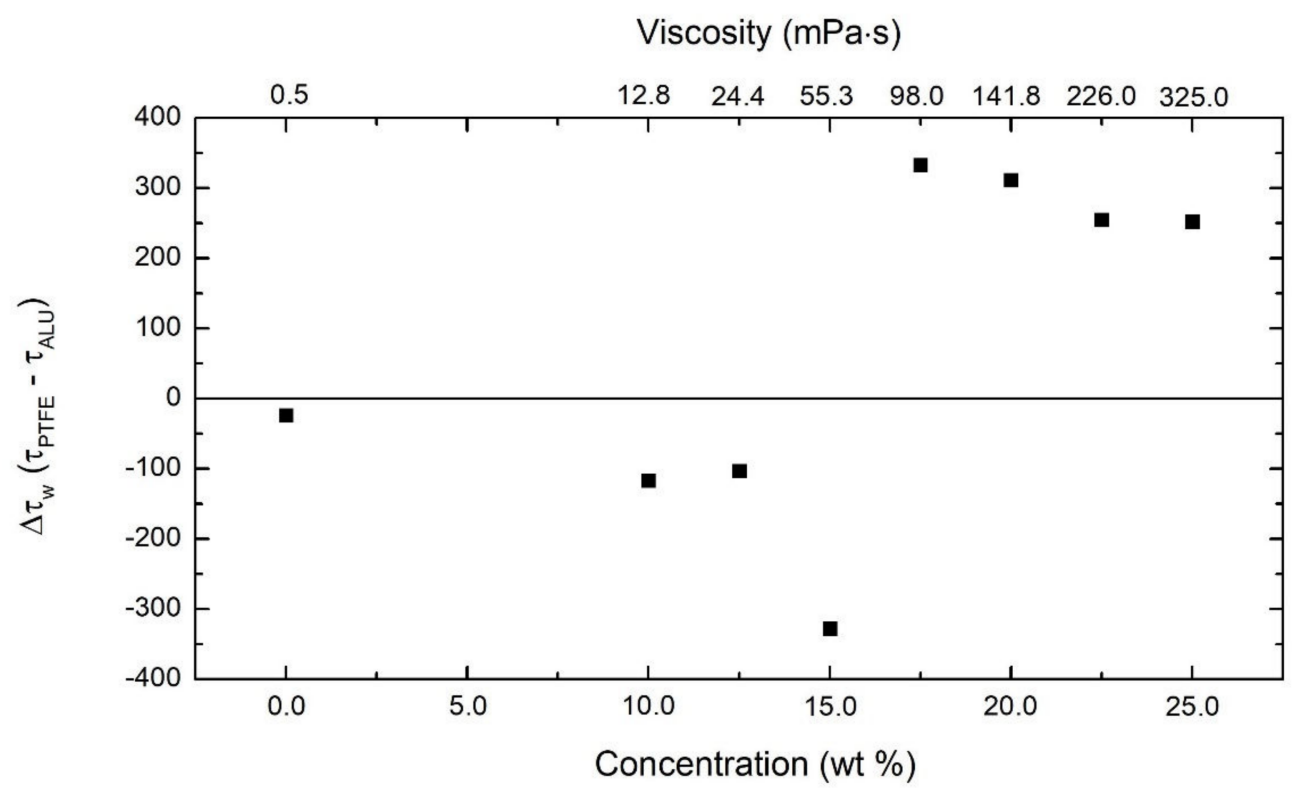

Figure 6. The difference in stress needed to push the polymer solution through PTFE and aluminum nozzles, respectively, as a function of the polymer concentration.

In Figure 7, the average fiber diameters for the samples spun with both the aluminum (squares) and the PTFE nozzle (circles) is plotted as a function of the polymer concentration, showing that the influence of polymer concentration on the fiber diameter is different for both nozzles. In the lower polymer concentration region, the diameter of the fibers spun from the PTFE nozzle increases with concentration (with a slope $=0.25$ ), almost similar to that spun from the aluminum nozzle (slope $=$ 0.13). In the higher-concentration region, the diameter of the fibers spun from the aluminum nozzle increases significantly faster (slope $=2.62$ ) than it does for the PTFE nozzle (slope $=0.90$ ).

This means that during the transition from a low to a high concentration region, the change in diameter is significantly less pronounced for fibers produced from the PTFE nozzle than from aluminum nozzle. The concentration region in which this increase in fiber diameter sets in is referred to as the transition region in Figure 7, within the gray zone, where the slopes of the two concentration regions intersect. This transition region also marks the change in fiber morphology from BOAS to bead-free fibers. The difference between the nozzle types shows that not only the polymer concentration (and therefore the viscosity) but also the nozzle material plays a significant role in the centrifugal fiber spinning process. In other words, the interaction of the polymer solution with the nozzle walls is of 
importance in order to be able to control the centrifuge fiber spinning process due to a significant flow inside the nozzles, as compared to other techniques where the flow rates are minimal.

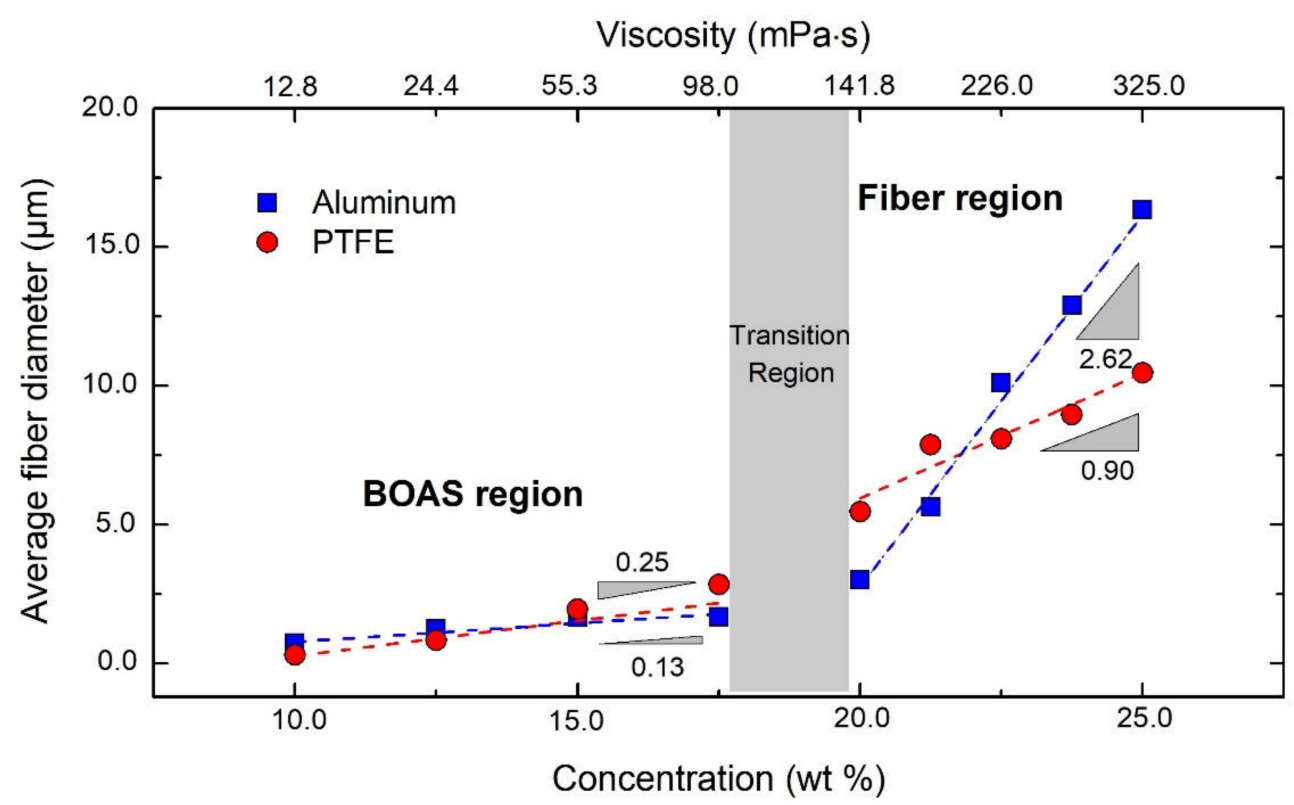

Figure 7. Change in fiber diameter as a function of polymer concentration for fibers spun using aluminum and PTFE nozzles. The error bars represent the standard deviations of the fiber diameters. Also given in the top $\mathrm{x}$-axis is the shear viscosity for each polymer concentration.

\section{Conclusions}

In this paper, we experimentally determined the influence of polymer concentration and nozzle material on the fiber diameter and morphology using a home-built centrifugal spinning setup. Viscosity measurements were performed on a wide range of PS solutions, ranging from 1.0 to $25.0 \mathrm{wt} \%$. The rheological measurements led to a transition of the power law exponent from 1.96 to 3.54, for the relationship between the specific viscosity and the normalized concentration. This transition corresponds to the change from an unentangled polymer system to an entangled one, and occurred at $\mathrm{c}_{\mathrm{e}} \approx 10 \mathrm{wt} \%$. From this concentration, the fiber spinning experiments were subsequently examined as a function of the polymer concentration up until $25.0 \mathrm{wt} \%$. These experiments revealed a morphological transition in the fiber samples from the beads-on-string morphology, for the lower-concentration region $(<17.5 \mathrm{wt} \%)$, to a continuous-fiber morphology, for the higher-concentration region $(>17.5 \mathrm{wt} \%)$. This morphological transition was accompanied by a significant change in the slope of the fiber diameter dependence on polymer concentration and therefore on solution viscosity.

Furthermore, this change was shown to be more significant for fibers produced from an aluminum nozzle, as compared to a PTFE nozzle having identical dimensions. This difference is attributed to the presence of a higher apparent wall slip in the case of an aluminum nozzle at the higher polymer concentrations, leading to a 'plug' flow through the nozzle and, subsequently, producing thicker fibers. The apparent wall slip behavior was shown to be present by measuring the difference between the force needed to push the solutions through the PTFE and the aluminum nozzles. This result led to the conclusion that, beyond a critical concentration, the polymer-nozzle wall interaction becomes significant and must be considered during fiber production, using centrifugal spinning and other spinning processes where there is a significant flow of polymer solution inside the nozzle.

Supplementary Materials: The following are available online at http://www.mdpi.com/2073-4360/12/3/575/s1, Figure S1: Exploded view of the assembly of the centrifugal fiber spinning setup.

Author Contributions: Conceptualization, J.M., W.M., and N.K.R.; methodology, J.M., and N.K.R.; validation, J.M. and N.K.R.; formal analysis, J.M.; investigation, J.M.; data curation, J.M.; writing—original draft preparation, 
J.M.; writing-review and editing, N.K.R., R.P., W.D., and M.B.; visualization, J.M.; supervision, N.K.R.; project administration, J.M. and N.K.R.; funding acquisition, N.K.R. All authors have read and agreed to the published version of the manuscript.

Funding: This research received no external funding.

Acknowledgments: The authors acknowledge IMO-IMOMEC at the University of Hasselt for providing financial support. The Packaging Technology Center is acknowledged for providing access to the tensile testing machine and Pieter Samyn for access to the scanning electron microscope. The authors thank Vivek Sharma and Ruth Cardinaels for their close reading of the manuscript.

Conflicts of Interest: The authors declare no conflict of interest.

\section{References}

1. Barhoum, A.; Rasouli, R.; Yousefzadeh, M.; Rahier, H.; Bechelany, M. Nanofiber Technology: History and Developments. In Handbook of Nanofibers; Barhoum, A., Bechelany, M., Makhlouf, A., Eds.; Springer International Publishing: Cham, Switzerland, 2018; pp. 1-42. [CrossRef]

2. Huang, Z.-M.; Zhang, Y.Z.; Kotaki, M.; Ramakrishna, S. A review on polymer nanofibers by electrospinning and their applications in nanocomposites. Compos. Sci. Technol. 2003, 63, 2223-2253. [CrossRef]

3. Maity, S.; Gon, D.P.; Paul, P. A review of flax nonwovens: Manufacturing, properties, and applications. J. Nat. Fibers 2014, 11, 365-390. [CrossRef]

4. Yoon, K.; Hsiao, B.S.; Chu, B. Functional nanofibers for environmental applications. J. Mater. Chem. 2008, 18, 5326-5334. [CrossRef]

5. Malwal, D.; Gopinath, P. Fabrication and applications of ceramic nanofibers in water remediation: A review. Crit. Rev. Environ. Sci. Technol. 2016, 46, 500-534. [CrossRef]

6. Filatov, Y.; Budyka, A.; Kirichenko, V. Electrospinning of micro-and nanofibers: Fundamentals in separation and filtration processes. J. Eng. Fibers Fabr. 2007, 3, 488.

7. Calderón, M.Á.R.; Zhao, W. Applications of polymer nanofibers in bio-materials, biotechnology and biomedicine: A review. In Proceedings of the TMS 2014: 143rd Annual Meeting \& Exhibition, San Diego, CA, USA, 16-20 February 2014; pp. 401-414.

8. Pham, Q.P.; Sharma, U.; Mikos, A.G. Electrospinning of polymeric nanofibers for tissue engineering applications: A review. Tissue Eng. 2006, 12, 1197-1211. [CrossRef]

9. Venugopal, J.; Ramakrishna, S. Applications of polymer nanofibers in biomedicine and biotechnology. Appl. Biochem. Biotechnol. 2005, 125, 147-157. [CrossRef]

10. Ding, B.; Yu, J. Electrospun Nanofibers for Energy and Environmental Applications; Springer: Berlin/Heidelberg, Germany, 2014.

11. Thavasi, V.; Singh, G.; Ramakrishna, S. Electrospun nanofibers in energy and environmental applications. Energy Environ. Sci. 2008, 1, 205-221. [CrossRef]

12. Ramakrishna, S.; Fujihara, K.; Teo, W.-E.; Yong, T.; Ma, Z.; Ramaseshan, R. Electrospun nanofibers: Solving global issues. Mater. Today 2006, 9, 40-50. [CrossRef]

13. Wei, Q. Functional Nanofibers and Their Applications; Elsevier: Amsterdam, The Netherlands, 2012.

14. Min, X.; Sun, B.; Chen, S.; Fang, M.; Wu, X.; Liu, Y.G.; Abdelkader, A.; Huang, Z.; Liu, T.; Xi, K.; et al. A textile-based $\mathrm{SnO}_{2}$ ultra-flexible electrode for lithium-ion batteries. Energy Storage Mater. 2019, 16, 597-606. [CrossRef]

15. Doshi, J.; Reneker, D.H. Electrospinning process and applications of electrospun fibers. J. Electrost. 1995, 35, 151-160. [CrossRef]

16. Reneker, D.H.; Chun, I. Nanometre diameter fibres of polymer, produced by electrospinning. Nanotechnology 1996, 7, 216. [CrossRef]

17. Srinivasan, G.; Reneker, D.H. Structure and morphology of small diameter electrospun aramid fibers. Polym. Int. 1995, 36, 195-201. [CrossRef]

18. Zargham, S.; Bazgir, S.; Tavakoli, A.; Rashidi, A.S.; Damerchely, R. The effect of flow rate on morphology and deposition area of electrospun nylon 6 nanofiber. J. Eng. Fibers Fabr. 2012, 7, 155892501200700414. [CrossRef]

19. Bakar, S.; Fong, K.; Eleyas, A.; Nazeri, M. Effect of voltage and flow rate electrospinning parameters on polyacrylonitrile electrospun fibers. In Proceedings of the IOP Conference Series: Materials Science and Engineering, Penang, Malaysia, 6-7 December 2017; p. 012076. 
20. Hutten, I.M. Chapter 5-Processes for Nonwoven Filter Media. In Handbook of Nonwoven Filter Media, 2nd ed.; Hutten, I.M., Ed.; Butterworth-Heinemann: Oxford, UK, 2016; pp. 276-342. [CrossRef]

21. Badrossamay, M.R.; McIlwee, H.A.; Goss, J.A.; Parker, K.K. Nanofiber Assembly by Rotary Jet-Spinning. Nano Lett. 2010, 10, 2257-2261. [CrossRef]

22. Mellado, P.; McIlwee, H.A.; Badrossamay, M.R.; Goss, J.A.; Mahadevan, L.; Kit Parker, K. A simple model for nanofiber formation by rotary jet-spinning. Appl. Phys. Lett. 2011, 99, 203107. [CrossRef]

23. Golecki, H.M.; Yuan, H.; Glavin, C.; Potter, B.; Badrossamay, M.R.; Goss, J.A.; Phillips, M.D.; Parker, K.K. Effect of solvent evaporation on fiber morphology in rotary jet spinning. Langmuir 2014, 30, 13369-13374. [CrossRef]

24. Ren, L.; Ozisik, R.; Kotha, S.P.; Underhill, P.T. Highly Efficient Fabrication of Polymer Nanofiber Assembly by Centrifugal Jet Spinning: Process and Characterization. Macromolecules 2015, 48, 2593-2602. [CrossRef]

25. McEachin, Z.; Lozano, K. Production and characterization of polycaprolactone nanofibers via forcespinning ${ }^{\mathrm{TM}}$ technology. J. Appl. Polym. Sci. 2012, 126, 473-479. [CrossRef]

26. Lu, Y.; Li, Y.; Zhang, S.; Xu, G.; Fu, K.; Lee, H.; Zhang, X. Parameter study and characterization for polyacrylonitrile nanofibers fabricated via centrifugal spinning process. Eur. Polym. J. 2013, 49, 3834-3845. [CrossRef]

27. Ren, L.; Pandit, V.; Elkin, J.; Denman, T.; Cooper, J.A.; Kotha, S.P. Large-scale and highly efficient synthesis of micro-and nano-fibers with controlled fiber morphology by centrifugal jet spinning for tissue regeneration. Nanoscale 2013, 5, 2337-2345. [CrossRef] [PubMed]

28. Sun, J.; Zhang, Z.; Lu, B.; Mei, S.; Xu, Q.; Liu, F. Research on parametric model for polycaprolactone nanofiber produced by centrifugal spinning. J. Braz. Soc. Mech. Sci. Eng. 2018, 40, 186. [CrossRef]

29. Ravishankar, P.; Khang, A.; Laredo, M.; Balachandran, K. Using Dimensionless Numbers to Predict Centrifugal Jet-Spun Nanofiber Morphology. J. Nanomater. 2019, 2019. [CrossRef]

30. Tepekiran, B.N.; Calisir, M.D.; Polat, Y.; Akgul, Y.; Kilic, A. Centrifugally spun silica $\left(\mathrm{SiO}_{2}\right)$ nanofibers for high-temperature air filtration. Aerosol Sci. Technol. 2019, 53, 921-932. [CrossRef]

31. Yang, S.B.; Yeum, J.H. Morphological Comparison of Aligned Poly(vinyl alcohol) Nanofibers Fabricated by Modified Electrospinning and Centrifugal Jet Spinning Techniques. J. Nanosci. Nanotechnol. 2017, 17, 9056-9062. [CrossRef]

32. Fauzi, A.; Edikresnha, D.; Munir, M.M. Synthesis of Styrofoam Fibers Using Rotary Forcespinning Technique. In Materials Science Forum; Trans Tech Publications Ltd.: Stafa-Zurich, Switzerland, 2015; pp. 279-284.

33. Weng, B.C.; Xu, F.H.; Garza, G.; Alcoutlabi, M.; Salinas, A.; Lozano, K. The Production of Carbon Nanotube Reinforced Poly(vinyl) Butyral Nanofibers by the Forcespinning (R) Method. Polym. Eng. Sci. 2015, 55, 81-87. [CrossRef]

34. Zander, N.E. Formation of melt and solution spun polycaprolactone fibers by centrifugal spinning. J. Appl. Polym. Sci. 2015, 132. [CrossRef]

35. Zhmayev, Y.; Divvela, M.J.; Ruo, A.C.; Huang, T.; Joo, Y.L. The jetting behavior of viscoelastic Boger fluids during centrifugal spinning. Phys. Fluids 2015, 27, 123101. [CrossRef]

36. Du, J.; Liu, D.B.; Chen, S.Q.; Wan, D.C.; Pu, H.T. A novel method for fabricating continuous polymer nanofibers. Polymer 2016, 102, 209-213. [CrossRef]

37. Li, X.L.; Chen, H.H.; Yang, B. Centrifugally spun starch-based fibers from amylopectin rich starches. Carbohydr. Polym. 2016, 137, 459-465. [CrossRef]

38. Andrade, P.O.; Santo, A.M.E.; Costa, M.M.; Lobo, A.O. Production of rotary jet spun ultrathin fibers of poly-butylene adipate-co- terephthalate (PBAT) filled with nanocomposites. In Advances in Microscopic Imaging; Beaurepaire, E., Pavone, F.S., So, P.T.C., Eds.; OSA Publishing: Washington, DC, USA, 2017; Volume 10414.

39. Vo, P.; Doan, H.; Kinashi, K.; Sakai, W.; Tsutsumi, N.; Huynh, D. Centrifugally Spun Recycled PET: Processing and Characterization. Polymers 2018, 10, 680. [CrossRef] [PubMed]

40. Xiong, C.D.; Li, X.L.; Hou, T.; Yang, B. Stability and spinnability of modified melamine-formaldehyde resin solution for centrifugal spinning. J. Appl. Polym. Sci. 2018, 135, 46072. [CrossRef]

41. Padilla-Gainza, V.; Morales, G.; Rodriguez-Tobias, H.; Lozano, K. Forcespinning technique for the production of poly(D,L-lactic acid) submicrometer fibers: Process-morphology-properties relationship. J. Appl. Polym. Sci. 2019, 136, 47643. [CrossRef] 
42. Noroozi, S.; Alamdari, H.; Arne, W.; Larson, R.G.; Taghavi, S.M. Regularized string model for nanofibre formation in centrifugal spinning methods. J. Fluid Mech. 2017, 822, 202-234. [CrossRef]

43. Taghavi, S.M.; Larson, R.G. Regularized thin-fiber model for nanofiber formation by centrifugal spinning. Phys. Rev. E 2014, 89, 023011. [CrossRef]

44. Zhiming, Z.; Jun, S.; Yaoshuai, D.; Binbin, L. Research on modeling, simulation and experiment based on centrifugal spinning method. J. Braz. Soc. Mech. Sci. Eng. 2018, 40, 488. [CrossRef]

45. Ren, L.; Kotha, S.P. Centrifugal jet spinning for highly efficient and large-scale fabrication of barium titanate nanofibers. Mater. Lett. 2014, 117, 153-157. [CrossRef]

46. Ewoldt, R.H.; Johnston, M.T.; Caretta, L.M. Experimental challenges of shear rheology: How to avoid bad data. In Complex Fluids in Biological Systems; Springer: Berlin/Heidelberg, Germany, 2015; pp. 207-241.

47. Barnes, H.A.; Hutton, J.F.; Walters, K. An Introduction to Rheology; Elsevier: Amsterdam, The Netherlands, 1989.

48. Macosko, C.W.; Larson, R.G. Rheology: Principles, Measurements, and Applications; Wiley-VCH: New York, NY, USA, 1994.

49. Graessley, W.W. Polymer chain dimensions and the dependence of viscoelastic properties on concentration, molecular weight and solvent power. Polymer 1980, 21, 258-262. [CrossRef]

50. Clasen, C.; Plog, J.P.; Kulicke, W.-M.; Owens, M.; Macosko, C.; Scriven, L.E.; Verani, M.; McKinley, G.H. How dilute are dilute solutions in extensional flows? J. Rheol. 2006, 50, 849-881. [CrossRef]

51. Fetters, L.J.; Hadjichristidis, N.; Lindner, J.S.; Mays, J.W. Molecular Weight Dependence of Hydrodynamic and Thermodynamic Properties for Well-Defined Linear Polymers in Solution. J. Phys. Chem. Ref. Data 1994, 23, 619-640. [CrossRef]

52. Palangetic, L.; Reddy, N.K.; Srinivasan, S.; Cohen, R.E.; McKinley, G.H.; Clasen, C. Dispersity and spinnability: Why highly polydisperse polymer solutions are desirable for electrospinning. Polymer 2014, 55, 4920-4931. [CrossRef]

53. Srinivasan, S.; Chhatre, S.S.; Mabry, J.M.; Cohen, R.E.; McKinley, G.H. Solution spraying of poly (methyl methacrylate) blends to fabricate microtextured, superoleophobic surfaces. Polymer 2011, 52, 3209-3218. [CrossRef]

54. Shenoy, S.L.; Bates, W.D.; Frisch, H.L.; Wnek, G.E. Role of chain entanglements on fiber formation during electrospinning of polymer solutions: Good solvent, non-specific polymer-polymer interaction limit. Polymer 2005, 46, 3372-3384. [CrossRef]

55. McKee, M.G.; Wilkes, G.L.; Colby, R.H.; Long, T.E. Correlations of solution rheology with electrospun fiber formation of linear and branched polyesters. Macromolecules 2004, 37, 1760-1767. [CrossRef]

56. Haward, S.J.; Sharma, V.; Butts, C.P.; McKinley, G.H.; Rahatekar, S.S. Shear and Extensional Rheology of Cellulose/Ionic Liquid Solutions. Biomacromolecules 2012, 13, 1688-1699. [CrossRef] [PubMed]

57. Rubinstein, M.; Colby, R.H. Polymer Physics; Oxford University Press: New York, NY, USA, 2003; Volume 23.

58. Colby, R.H. Structure and linear viscoelasticity of flexible polymer solutions: Comparison of polyelectrolyte and neutral polymer solutions. Rheol. Acta 2010, 49, 425-442. [CrossRef]

59. Doan, H.N.; Nguyen, D.K.; Vo, P.P.; Hayashi, K.; Kinashi, K.; Sakai, W.; Tsutsumi, N.; Huynh, D.P. Facile and Scalable Fabrication of Porous Polystyrene Fibers for Oil Removal by Centrifugal Spinning. ACS Omega 2019, 4, 15992-16000. [CrossRef]

60. Li, Y.; Zou, C.; Shao, J.; Zhang, X. Preparation of $\mathrm{SiO}_{2} / \mathrm{PS}$ superhydrophobic fibers with bionic controllable micro-nano structure via centrifugal spinning. RSC Adv. 2017, 7, 11041-11048. [CrossRef]

61. Leng, G.; Zhang, X.; Shi, T.; Chen, G.; Wu, X.; Liu, Y.; Fang, M.; Min, X.; Huang, Z. Preparation and properties of polystyrene/silica fibres flexible thermal insulation materials by centrifugal spinning. Polymer 2019, 185, 121964. [CrossRef]

62. Eggers, J. Nonlinear dynamics and breakup of free-surface flows. Rev. Mod. Phys. 1997, 69, 865. [CrossRef]

63. Clasen, C.; Bico, J.; Entov, V.; McKinley, G. 'Gobbling drops': The jetting-dripping transition in flows of polymer solutions. J. Fluid Mech. 2009, 636, 5-40. [CrossRef]

64. Dinic, J.; Zhang, Y.; Jimenez, L.N.; Sharma, V. Extensional Relaxation Times of Dilute, Aqueous Polymer Solutions. ACS Macro Lett. 2015, 4, 804-808. [CrossRef]

65. Oliveira, M.S.; Yeh, R.; McKinley, G.H. Iterated stretching, extensional rheology and formation of beads-on-a-string structures in polymer solutions. J. Non-Newton. Fluid Mech. 2006, 137, 137-148. [CrossRef] 
66. Bhat, P.P.; Appathurai, S.; Harris, M.T.; Pasquali, M.; McKinley, G.H.; Basaran, O.A. Formation of beads-on-a-string structures during break-up of viscoelastic filaments. Nat. Phys. 2010, 6, 625-631. [CrossRef]

67. Mhetar, V.; Archer, L.A. Slip in Entangled Polymer Solutions. Macromolecules 1998, 31, 6639-6649. [CrossRef]

68. Joshi, Y.M.; Lele, A.K.; Mashelkar, R. A unified wall slip model. J. Non-Newton. Fluid Mech. 2000, 94, $135-149$. [CrossRef]

69. Archer, L.; Chen, Y.L.; Larson, R. Delayed slip after step strains in highly entangled polystyrene solutions. J. Rheol. 1995, 39, 519-525. [CrossRef]

70. Denn, M.M. Extrusion instabilities and wall slip. Annu. Rev. Fluid Mech. 2001, 33, 265-287. [CrossRef]

71. Migler, K.; Liu, C.H.; Pine, D.J. Structure evolution of a polymer solution at high shear rates. Macromolecules 1996, 29, 1422-1432. [CrossRef]

72. Rezvantalab, H.; Zhu, G.R.; Larson, R.G. The effect of wall depletion and hydrodynamic interactions on stress-gradient-induced polymer migration. Soft Matter 2016, 12, 5883-5897. [CrossRef]

73. Neto, C.; Evans, D.R.; Bonaccurso, E.; Butt, H.-J.; Craig, V.S. Boundary slip in Newtonian liquids: A review of experimental studies. Rep. Prog. Phys. 2005, 68, 2859. [CrossRef]

74. Hatzikiriakos, S.G. Slip mechanisms in complex fluid flows. Soft Matter 2015, 11, 7851-7856. [CrossRef] [PubMed]

75. Malkin, A.Y.; Patlazhan, S.A. Wall slip for complex liquids-Phenomenon and its causes. Adv. Colloid Interface Sci. 2018, 257, 42-57. [CrossRef] [PubMed]

76. Hemminger, O.; Boukany, P.E. Microscopic origin of wall slip during flow of an entangled DNA solution in microfluidics: Flow induced chain stretching versus chain desorption. Biomicrofluidics 2017, 11, 044118. [CrossRef]

77. Wang, S.Q. From Wall Slip to Bulk Shear Banding in Entangled Polymer Solutions. Macromol. Chem. Phys. 2019, 220, 1800327. [CrossRef]

(C) 2020 by the authors. Licensee MDPI, Basel, Switzerland. This article is an open access article distributed under the terms and conditions of the Creative Commons Attribution (CC BY) license (http://creativecommons.org/licenses/by/4.0/). 